\title{
A Case Involving Needles in the Medulla Oblongata, Cervical Spinal Cord, and Abdomen
}

\author{
Hao-Yu Zhang, Da Li, Zhen Wu, Li-Wei Zhang, and Jun-Ting Zhang
}

It is extremely rare to encounter intracranial foreign bodies caused by penetrating injuries other than gunshot wounds or low-velocity wounds. We present a case describing a 5-year-old girl with metallic foreign bodies in the medulla oblongata, cervical spinal cord, and abdomen. The foreign bodies may have been there and remained silent for several years until the patient developed nausea and vomiting that persisted for 3 months. A craniotomy and a laparotomy were performed after a thorough discussion. Five pieces of metallic foreign bodies were removed, and the patient had a good outcome. Despite the precarious location of the needles in the medulla oblongata and cervical spinal cord, this rare case supports the use of surgery to remove the foreign bodies.

Keywords: abdomen, brainstem, cervical cord, medulla oblongata, needles

\section{Introduction}

Penetrating injuries of the brain are rarely seen in civilians. Although 8 cases have been reported, intracranial foreign bodies after penetrating injuries that involve the brainstem are extremely rare. ${ }^{1-10)}$ Moreover, few patients suffering from several penetrating injuries by multiple needles have been reported. In this article, we present a case involving multiple needles in the medulla oblongata, cervical spinal cord, and abdomen. The study was approved by the Beijing Tiantan Hospital Research Ethics Committee. Informed consent was obtained from the patient and her parents.

\section{Case Report}

A 5-year-old girl was admitted to the hospital with nausea and vomiting that had persisted for 3 months. No significant abnormalities were observed during the neurological examinations. The electromyogram was within normal limits. Cerebral computed tomography (CT) and an abdominal $\mathrm{X}$-ray revealed metallic foreign bodies in the medulla oblongata, spinal canal (cervical vertebrae C6-C7), and upper right abdomen (Fig. 1). The pre-operative CT angiogram (CTA) revealed that the intracranial foreign body was discontinuous and was in close proximity to the confluence of the ambilateral vertebral arteries; the foreign body in the spinal canal was near the left vertebral artery at the level of

Department of Neurosurgery, Beijing Tiantan Hospital, Capital Medical University, Beijing, China

Received: October 23, 2013; Accepted: December 6, 2013
C7 (Fig. 2). No wounds or scars were found on the patient's skin, and her parents claimed that she was previously healthy and had no recent trauma.

After a thorough discussion of the risks and benefits, surgical operations were performed. Under intubated anesthesia and electrophysiological monitoring, the suboccipital posterior midline approach was performed first. The posterior arch of the atlas was also excised. After the dura mater was opened, a needle was found puncturing the right cerebellar tonsil and the medulla oblongata, extending to the clivus (Fig. 3a). We attempted to pull out the needle carefully. However, the needle was fragile and broke into pieces. We carefully removed the needle fragments one by one. The full length of the needle fragments was approximately $3.5 \mathrm{~cm}$ (Fig. 3b). Desmoplasia and a small amount of pus were observed around the needle. Next, the left lamina of the 6th cervical vertebra and the intervertebral foramen were exposed. The tip of the foreign body was found in the transverse foramen, and a needle that was $4 \mathrm{~cm}$ in length was completely removed (Fig. 3b). Brainstem tissue, nerves, and important vessels were well protected during the operations. The laparotomy was performed immediately after the neurosurgical procedures. A metallic foreign body, encapsulated by the greater omentum, was found in the upper right abdomen. We removed the foreign body and the encapsulating greater omentum. No ascites, intestinal adhesions, or injuries to the intestines or vessels were observed during the operation. The patient's recovery was uneventful, and no post-operative infections occurred.

A post-surgical neurological examination revealed a motor disturbance [manual muscle test (MMT) 4/5] and paresthesia in the right extremities, and a positive Romberg's sign. Four months later, only a slight motor disturbance (MMT 4+/5) in the right extremities remained, and the patient reported no paresthesia. This motor disturbance was still present at the patient's 2-year follow up examination.

The surface of the intracranial needles was covered with fibrous tissue and was examined with a microscope. Microscopically, we observed fibroblast hyperplasia, dispersed lymphocytes, and a large number of phagocytes, with few gliocytes around the periphery of the samples. Hemosiderin and inorganic salt deposition were also observed (Fig. 4).

\section{Discussion}

Intracranial foreign bodies resulting from penetrating injuries, other than those following gunshot wounds or lowvelocity wounds are extremely rare. ${ }^{3,8,11)}$ Intracranial needles involving the medulla oblongata and cervical spinal cord 

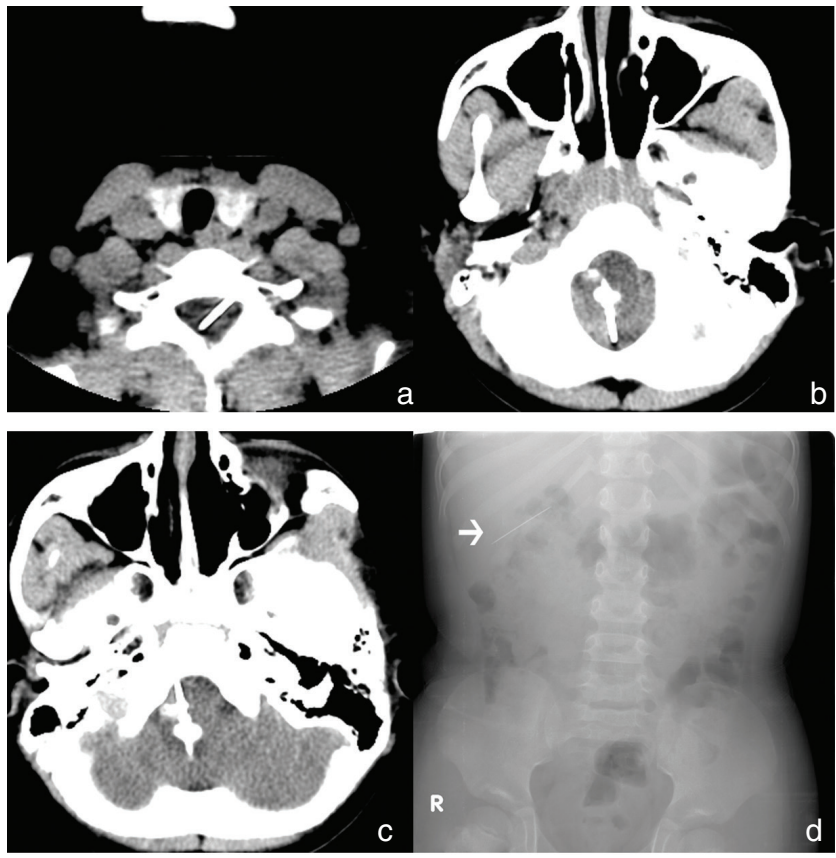

Fig. 1 a: Preoperative axial CT scan showing a metallic foreign body in the spinal canal (cervical vertebrae C6-C7). b, c: Preoperative axial $\mathrm{CT}$ scan showing metallic foreign bodies in the medulla oblongata (b) and extending to the clivus (c). d: Abdominal X-ray showing a metallic foreign body (white arrow) in the upper right abdomen. CT: computed tomography.

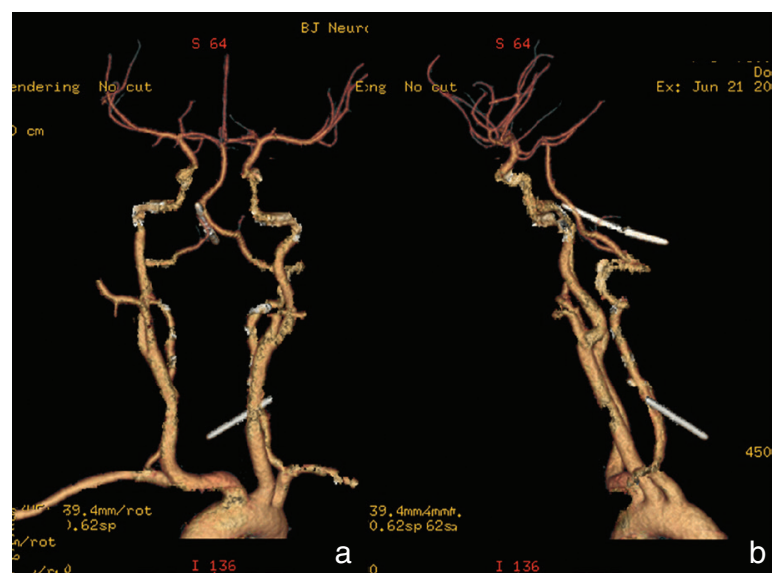

Fig. 2 Preoperative computed tomography angiography revealing that the intracranial foreign body was discontinuous and in close proximity to the confluence of the ambilateral vertebral arteries; the foreign body in the spinal canal was in close proximity to the left vertebral artery at the $\mathrm{C} 7$ level (a: anteroposterior position, b: lateral position).

have been reported in a limited number of cases (Table 1).1,2,10,12) Due to the eloquence of the neurovascular structures of the central nervous system, this case report is focused on the foreign bodies involving the medulla oblongata and cervical spinal cord.

The most common path for pediatric intracranial foreign bodies is transorbital penetration. ${ }^{13-15)}$ In these cases, the patients had a clear history of trauma, and wooden fragments were the most common foreign bodies. Most of the cases
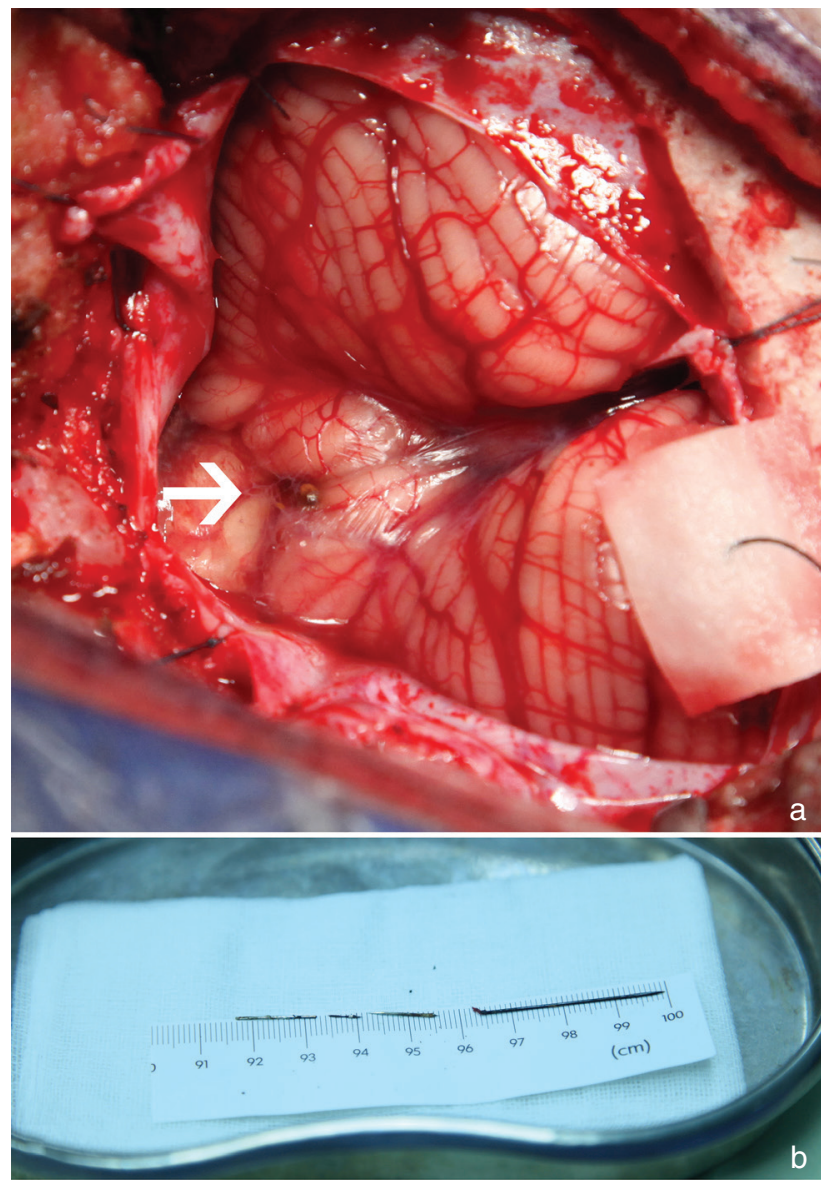

Fig. 3 a: A needle (white arrow) was found puncturing the right cerebellar tonsil and medulla oblongata. b: The full length of the needle fragments removed from the medulla oblongata was approximately $3.5 \mathrm{~cm}$ (the three needle fragments on the left side) and the needle removed from the spinal cord was approximately $4 \mathrm{~cm}$ (the needle on the right side).

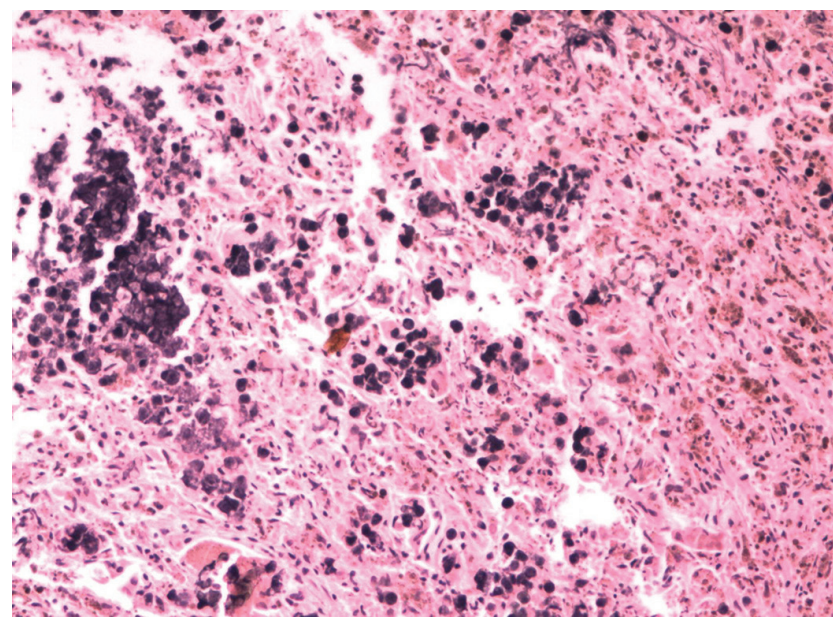

Fig. 4 Microscopically, fibroblast hyperplasia, dispersed lymphocytes, and a large number of phagocytes were observed, with few gliocytes around the periphery of the samples. Hemosiderin and inorganic salt deposition were also observed (hematoxylin and eosin staining, $\times 200)$. 
Table 1 Clinical data from published cases describing needles in the medulla oblongata

\begin{tabular}{|c|c|c|c|c|c|}
\hline Authors & $\operatorname{Age}(y) / \operatorname{sex}$ & Injury site & Symptoms & Treatment & Outcome \\
\hline Abumi et al. ${ }^{1)}$ & $60 / \mathrm{F}$ & $\begin{array}{l}\text { The left posterolateral to the right } \\
\text { anterolateral medulla oblongata at } \\
\text { the level of the foramen magnum }\end{array}$ & $\begin{array}{l}\text { Progressive motor and } \\
\text { sensory disturbances of } \\
\text { the right upper extremity }\end{array}$ & Operation & $\begin{array}{l}\text { Motor and sensory disturbances } \\
\text { diminished gradually and } \\
\text { disappeared } 2 \text { weeks after surgery }\end{array}$ \\
\hline Hama and $\mathrm{Kaji}^{2)}$ & 70/M & $\begin{array}{l}\text { The cervical spinal cord between } \\
\text { the } \mathrm{C} 1 \text { vertebra and the medulla } \\
\text { oblongata }\end{array}$ & None & Observation & $\begin{array}{l}\text { Developed increased left facial } \\
\text { paresthesia during the 1-year } \\
\text { period after the lesion was found }\end{array}$ \\
\hline Takahashi et al. ${ }^{9)}$ & $23 / \mathrm{F}$ & $\begin{array}{l}\text { The left medulla oblongata via } \\
\text { the great foramen }\end{array}$ & $\begin{array}{l}\text { Nausea, vomiting, motor } \\
\text { disturbance (MMT 3/5) } \\
\text { and hyperesthesia in the } \\
\text { bilateral upper extremities }\end{array}$ & Operation & $\begin{array}{l}\text { Only a slight motor disturbance } \\
\text { (MMT } 4+/ 5 \text { ) affecting left hand } \\
\text { grip strength and paresthesia in the } \\
\text { dorsum of the left hand remained } \\
5 \text { days after surgery }\end{array}$ \\
\hline Present case & $5 / \mathrm{F}$ & $\begin{array}{l}\text { The medulla oblongata at the level } \\
\text { of the confluence of the ambilateral } \\
\text { vertebral arteries; the spinal canal } \\
\text { (cervical vertebrae C6-C7) beside } \\
\text { the left vertebral artery; upper right } \\
\text { abdomen }\end{array}$ & Nausea and vomiting & Operation & $\begin{array}{l}\text { Motor disturbance (MMT 4/5) and } \\
\text { paresthesia in the right extremities, } \\
\text { positive Romberg's sign; only a } \\
\text { slight motor disturbance (MMT } \\
4+/ 5 \text { ) in the right extremities } \\
4 \text { months after surgery and } \\
\text { during following } 2 \text { years. }\end{array}$ \\
\hline
\end{tabular}

F: female, M: male, MMT: manual muscle test.

reporting intracranial needles involved child abuse and homicide attempts. ${ }^{16,17)}$ Although treated surgically, patients in these cases suffered from injury-related sequelae or died. In our case, the patient is the only child in her family. The exact mechanism of trauma is still unknown, but we assume that it was man-made. We suspect that the injury was caused by child abuse due to sex discrimination, which was mentioned by one of the patient's family members.

Abumi et al. ${ }^{1)}$ and Hama and Kaji et al. ${ }^{2)}$ reported two cases of acupuncture needles in the medulla oblongata, and both the patients were adults. Needles migrated into the medulla oblongata and spinal canal from subcutaneous locations in both cases and remained silent for a period of time. Several additional cases also reported the migration of foreign bodies in the central nervous system. ${ }^{2,8,18)}$ In our case, the patient had no recent trauma, and the needles were located in medulla oblongata and extended to the clivus. During the operation, we found that one of the needles had broken into three pieces due to corrosion. Desmoplasia and a small amount of pus were also observed around the needles. Fibroblast hyperplasia, hemosiderin, and inorganic salt deposition were observed under a microscope. All these evidences suggest that the needles might have been there for years and migrated into the medulla oblongata. They remained silent in the medulla oblongata and cervical spinal cord during these years.

Generally, neurological disturbances after direct needle trauma to the medulla oblongata are mild. Few cases presented symptoms immediately after the structures were punctured.9) This might be the case because the needles are tiny and have little space-occupying effects, therefore causing few severe neural and vascular injuries. The asymptomatic foreign bodies may become symptomatic due to compression of the neural elements and migration. ${ }^{1,2,12,18,19)}$ Akcakaya et al. ${ }^{12)}$ reported a case of an asymptomatic glass fragment in the spinal canal, which became symptomatic 21 years after the injury when it migrated to a narrow point in the spinal canal. In our case, the needles were found penetrating the medulla oblongata from the right caudal cerebellar tonsil to the left cranial medulla oblongata at the level of the confluence of the ambilateral vertebral arteries, and extending to the clivus. There were tight adhesions between the needles and the surrounding tissues. Although the needles were tiny, the extensive injuries to the medulla oblongata and the damage to the medulla oblongata tissue during their migration caused them to become symptomatic. During the operation, we dissected carefully the hyperplastic tissues that were surrounding the medulla oblongata. Unfortunately, although we performed the operation as delicately as possible, the patient experienced sequelae from the procedure. However, it was clear that the patient would experience more severe symptoms as the movement and the corrosion of the needles continued if the operation was not performed in time.

Furthermore, a severe inflammatory reaction may have occurred in the surrounding tissues in response to the metal. Others have found that copper and lead can produce a severe inflammatory reaction in the surrounding tissue..$^{1,9)}$ Pure gold produces the least severe inflammatory reaction of the various metals. In our case, the material of the needles is unknown. During the operation, desmoplasia and a small amount of pus were observed around the needle. Postoperative pathology also suggested that an inflammatory reaction had occurred. It seemed that the inflammatory reaction did not cause a severe outcome for this patient. It is possible that the limited nature of the reaction protected the nerve tissue.

Surgical removal of the foreign bodies appears to be the only way to resolve the associated problems, including the present symptoms, compression to the surrounding tissue, 
the toxicity of the metal, and the risk of nerve damage associated with the migration of the foreign bodies. Most of the cases involving foreign bodies were treated surgically. ${ }^{1,2,9,12}$ ) The pre-operative discussion must be individualized, comprehensive and detailed manner. CT is an effective method to investigate metallic foreign bodies. It is very important to evaluate the size and position of the foreign bodies. In some cases, CTA is necessary to obtain a full view of the location of the foreign bodies in relation to important vessels. In our case, the patient was a 5-year-old girl and her symptoms were mild. If the operation was not performed, the foreign bodies might have caused further severe symptoms and affect the patient's growth. However, the foreign bodies involved the medulla oblongata, cervical spinal canal (C6-C7 level), and the abdomen. CTA revealed that the foreign bodies were in close proximity to the vertebral arteries. The risk of this operation was quite high. The operation had to be very precise and delicately performed to avoid further injury to the surrounding tissues. Electrophysiological monitoring is a useful tool to minimize such injuries. In our case, considering the effect of intubated anesthesia on the patient, the foreign body in the abdomen was removed immediately after the neurosurgical procedures.

Most cases similar to ours reported good outcomes after surgical treatment. ${ }^{1,8,9,12,18)}$ It is important to prevent postoperative infection. Similar to our case, the most common complications were motor disturbances and paresthesia, but these symptoms improved several months after surgery.

\section{Conclusion}

Intracranial foreign bodies involving the brainstem and spinal cord are extremely rare. Such cases should be given a great deal of consideration, although sometimes the patient is asymptomatic. Surgical removal should be performed if possible. The preoperative preparation must be comprehensive and the procedure must be extremely precise to ensure the success of the operation. A good outcome can be achieved via surgery in most cases.

\section{Conflicts of Interest Disclosure}

The authors declare that they have no conflicts of interest.

\section{References}

1) Abumi K, Anbo H, Kaneda K: Migration of an acupuncture needle into the medulla oblongata. Eur Spine J 5: 137-139, 1996

2) Hama Y, Kaji T: A migrated acupuncture needle in the medulla oblongata. Arch Neurol 61: 1608, 2004

3) Hussain M, Bari ME: Suicide bomb attack causing penetrating craniocerebral injury. Chin J Traumatol 16: 51-53, 2013

4) Ishi N, Umezaki H, Mukai K: [A case of brainstem trauma due to insertion of a sewing needle]. No Shinkei Geka 5: 1395-1398, 1977 (Japanese)

5) Lazic T, Strugar J: Nail in the midbrain. Neurology 72: 1531, 2009

6) Luo W, Liu H, Hao S, Zhang Y, Li J, Liu B: Penetrating brain injury caused by nail guns: two case reports and a review of the literature. Brain Inj 26: 1756-1762, 2012

7) Paiva WS, de Andrade AF, Amorim RL, Figueiredo EG, Teixeira MJ: Brainstem injury by penetrating head trauma with a knife. Br J Neurosurg 26: 779-781, 2012

8) Rammo RA, DeFazio MV, Bullock MR: Management of migrating intracranial bullets: lessons learned from surviving an AK-47 bullet through the lateral brainstem. World Neurosurg 77: 591.e19-e24, 2012

9) Takahashi K, Morimura N, Sakamoto T, Nagashima H, Hirata M: Medullar injury caused by sewing needle puncture. J Emerg Med 40: 65-67, 2011

10) Xu F, Li J, Sun S, Guo E, Hao S, Hou Z, Leung GK, Liu B: The surgical management of a penetrating orbitocranial injury with a Bakelite foreign body reaching the brain stem. Brain Inj 27: 951-956, 2013

11) Singh D, Gupta V, Kataria R, Chopra S, Gupta P, Bagaria H: An unusual presentation of head injury: teeth in brain. Turk Neurosurg 20: 63-65, 2010

12) Akcakaya MO, Aras Y, Yorukoglu AG, Ovalioglu C, Sencer A: Cervical intradural glass fragment: a rare cause of neuropathic pain. Turk Neurosurg 22: 667-670, 2012

13) Mitilian D, Charon B, Brunelle F, Di Rocco F: Removal of a chopstick out of the cavernous sinus, pons, and cerebellar vermis through the superior orbital fissure. Acta Neurochir (Wien) 151: 1295-1297, 2009

14) Sanli AM, Kertmen H, Yilmaz ER, Sekerci Z: A retained wood penetrating the superior orbital fissure in a neurologically intact child. Turk Neurosurg 22: 393-397, 2012

15) Shah AD, Decock C: Occult orbito-cranial penetrating injury by pencil: role of beta tracer protein as a marker for cerebrospinal fluid leakage. Indian J Ophthalmol 59: 505-507, 2011

16) Amirjamshidi A, Ghasvini AR, Alimohammadi M, Abbassioun K: Attempting homicide by inserting sewing needle into the brain Report of 6 cases and review of literature. Surg Neurol 72: 635-641; discussion 641, 2009

17) Jacob JT, Cohen-Gadol AA, Maher CO, Meyer FB: Transorbital penetrating brainstem injury in a child: case report. J Neurosurg 102: 350352, 2005

18) Yoshioka K, Kawahara N, Murakami H, Demura S, Matsuda M, Tomita K: A glass foreign body migrating into the lumbar spinal canal: a case report. J Orthop Surg (Hong Kong) 20: 257-259, 2012

19) Deveer M, Imamoglu F, Imamoglu C, Okten S: An incidental case of asymptomatic intracranial foreign body on CT. BMJ Case Rep 2013, 2013 